\title{
A CULTURA DA INSTABILIDADE POLÍTICA E A REAPROXIMAÇÃO DA AMÉRICA DO SUL COM OS ESTADOS UNIDOS
}

\author{
Henrique Carlos de Oliveira de Castro $^{2}$ \\ Sonia Ranincheski ${ }^{3}$
}

\section{Introdução}

Em alguns países da América do Sul, a história de extrema pobreza e de desigualdades sociais tem sido reescrita. Diferente dos anos I980, marcados pelos governos chamados neoliberais e dos receituários do FMI, motivados pelo Consenso de Washington, os governos dos três países andinos - Venezuela, Equador e Bolívia - vêm implementando políticas e projetos sociais com relativo sucesso nos últimos i6 anos.

Os projetos de assistência e redistribuição de renda, moradia, saúde, educação, políticas protecionistas e nacionalização das riquezas naturais, além de implementarem novas formas de participação política da sociedade, vêm contribuindo para acirrar as disputas ideológicas nacional e internacionalmente. No entanto, a partir de 2015, instabilidades políticas têm despertado o debate sobre o futuro destes três países e as suas consequências para

I Agradecemos ao doutorando de Ciência Política da UFRGS, Flávio Busnello, pela dedicação no levantamento de dados para este artigo.

2 Doutor em Ciência Política pela Universidade Federal do Rio Grande do Sul (UFRGS). Estágio pós-doutoral na École de hautes étude en sciences sociales (EHESS, Paris). Professor do Programa de Pós-Graduação em Ciência Política, do Programa de Pós-Graduação em Estudos Estratégicos Internacionais e do curso de graduação em Relações Internacionais da UFRGS. E-mail: henrique@ufrgs.br

3 Doutora em Sociologia pela Universidade de Brasília. Estágio pós-doutoral na École de hautes étude en sciences sociales (EHESS, Paris). Professora dos Programas de Pós-Graduação em Ciência Política e em Estudos Estratégicos Internacionais e do curso de graduação em Relações Internacionais da UFRGS. E-mail: ranincheski.s@gmail.com 
a política externa. O presente artigo discute a política externa dos três países andinos e a sua relação com os Estados Unidos, levando em conta as atuais crises políticas venezuelana, equatoriana e boliviana.

No final dos anos I990, a América do Sul entra em uma fase de polarização entre governos que afirmam uma suposta continuidade institucional e os governos de Hugo Chávez (Venezuela), de Evo Morales (Bolívia) e Rafael Correa (Equador), que proclamam uma disposição de refundar o Estado e a democracia social. A atuação destes mandatários produzem tensões que se irradiam na região e suas ações não se restringem aos seus respectivos países, mas ampliam as suas referências políticas e usam identidades culturais e históricas supranacionais, como é o caso de Simon Bolívar.

Se na política interna há mudanças expressivas, considerando o passado de pobreza destes países, na política externa igualmente notam-se mudanças significativas, decorrentes das decisões domésticas. Estes governos acentuam a estratégia da cooperação e integração entre os países latino-americanos, a aproximação com a China e a Rússia, os acordos de cooperação SulSul. Uma outra decisão tomada pelos três países e que afetaria a relação externa foi a nacionalização dos recursos minerais e energéticos explorados até então por empresas norte-americanas e europeias. Assim, em muita medida, os interesses dos Estados Unidos foram afetados na região.

Determinados autores defendem uma crescente irrelevância da América Latina para os Estados Unidos, acentuada pelos eventos de onze de setembro de 200I (Ayerbe 2008, Fuentes 2004). O descaso dos Estados Unidos pela região parece pouco compreensível, haja vista os interesses norte-americanos nos recursos minerais e energéticos da região (entre outros). Uma vasta literatura sobre a histórica dominação norte-americana na América Latina (Bandeira 2010, Ayerbe 2002, Pecequilo 20II e 2012, Nye I990 e 2002, Kagan 20I2, Vizentini e Wiesebron 2006) mostra que os EUA sempre prestaram atenção no continente, mormente as diferentes estratégias adotadas.

O presidente americano Woodrow Wilson transformou a visão que os Estados Unidos tinham elaborado, em grande medida para seu consumo interno, no início do século XX, num programa operacional passível de ser aplicado ao mundo inteiro. A partir de então, o mundo se sentiu impelido a lhe dar atenção, tanto pela força dos Estados Unidos, quanto pelo alcance de sua visão (Kissinger 20I5, 485). Se esse pensamento ainda é vigente, o aparente desinteresse norte-americano com a região, defendida por alguns círculos, não faria sentido. Com efeito, os Estados Unidos parecem interessados nos desdobramentos das atuais crises nos três países andinos. Elementos para constituir respostas a estas indagações são apresentados a seguir a partir da 
análise da política interna e externa dos três países andinoss.

\section{A política externa da Venezuela, Equador e Bolívia: política “desde abajo"; Pátria, altiva, digna e soberana; sócios, não patrões}

A política externa da Venezuela, com a entrada de Hugo Chavez, é marcada pela multipolaridade, pelo nacionalismo e a defesa da integração latino-americana. Estes três pilares são encontrados nas políticas equatorianas e bolivianas, respectivamente nos governos de Rafael Correa e Evo Morales. Se trata de exportação das ideias chavistas? Parece simplista o argumento de transposição do modelo chavista por desconsiderar que havia (ou há) um mesmo modelo de dominação e lógica capitalista a serem enfrentados nestes países. A nacionalização e controle das riquezas naturais foram pontos centrais para Chavez, mas a origem motivacional destas ações se constituem em lutas históricas da região e já foram tentadas outras vezes em outros países. É o caso da Bolívia em I952 e a nacionalização das minas controladas pelos grupos Patiño, Hochschild e Aramayo. Como afirmou Marx em conhecida passagem de "O Manifesto Comunista", apesar das particularidades nacionais, o trabalho industrial e a subjugação moderna ao capital são as mesmas em todos os países, o que lhes tirou todo o caráter nacional.

\section{A Política externa “desde abajo" de Hugo Chavez}

A política externa de Hugo Chavez, seguida pelo seu sucessor Nicolás Maduro $^{4}$, apresenta três vertentes: a confrontação com os EUA, a busca de posição dominante da Venezuela na América Latina através da criação da Alba (Alternativa Bolivariana para as Américas) e as relações com o Brasil e o Mercosul (Carmo 2008). A estratégia de Chavez seria fortalecer-se internamente e buscar apoio internacional para o seu projeto nacional. Para tanto, com o discurso e a política do fim das desigualdades sociais - uma política para "los de abajo" -, Chavez amplia essa perspectiva para a cena internacional.

4 Chavez ficou I4 anos direto no governo. É eleito por voto popular em I998 para cinco anos de mandato. Para modificar a Constituição e aumentar o poder do presidente, foi realizado um referendo logo que eleito. Com a mudança, foi preciso realizar outra eleição, e Chávez foi eleito novamente em 200I. Assume o mandato de 2000 a 2007. Nas eleições de 2006 é reeleito para mais um mandato, até 2012 . Nas eleições seguintes, é eleito para o terceiro mandato, mas falece em 20I3. É convocada nova eleição presidencial e ganha o sucessor político de Chaves, Nicolás Maduro. 
Internamente e politicamente foi desfeito o modelo democrático liberal vigente durante 42 anos baseado em dois partidos - Acción Democrática, de tendência social-democrata, e Copei, democrata-cristão de centro-direita. O governo de Chavez, aliado a movimentos sociais, implementa uma nova Constituição, em 2007, com referendo popular, e com ela afeta estruturas políticas e jurídicas do país, alijando as elites tradicionais das decisões. Esse confronto interno exige apoio externo. A aproximação e cooperação estreita com Cuba - vendendo petróleo a este país por preços abaixo do mercado, a partir de I999 - é uma estratégia inserida nesta lógica de aproximação com países identificados com projeto social de Chavez.

A ideia de uma política externa "desde abajo" segue o mesmo princípio interno de maximizar as políticas sociais e obter apoio popular; desta forma, Chavez implementa uma estratégia multipolar e de apoio aos países latino-americanos (Ellner 2008). A política externa venezuelana ganha forte contorno regional, destacando-se pela defesa dos interesses da região e o confronto direto com outros interesses internacionais. A política externa deve então reforçar as alianças entre os países com governos progressistas, os vínculos com os demais países da região e com potências fora da zona de influência norte-americana. No arco das alianças latino-americanas, Chavez se distanciaria dos presidentes Vicente Fox do México e Alan Garcia do Peru por seus vínculos com os Estados Unidos e de determinados organismos e agências internacionais por se tratarem, em seu ponto de vista, de representantes dos interesses norte-americanos.

Para reforçar essa estratégia de relações desde abajo, em 2006, Chavez retira a Venezuela da Comunidade Andina das Nações (CAN) em resposta aos acordos bilaterais que Peru e Colômbia haviam firmado com os Estados Unidos. Segundo Ellner (2008), para Chavez, "esos acuerdos favorecen a las elites y a las transnacionales, pero no sirven a los intereses de los indígenas, los negros o los pobres". Simultaneamente o presidente venezuelano lidera a formação da Unasul e pressiona para entrar no Mercosul, algo que ocorrerá em julho de 2012 .

O distanciamento entre Caracas e Washington foi se constituindo à medida que políticas de Chavez tais como como nacionalização da exploração dos recursos minerais, sobretudo o petróleo, com a criação companhia petrolífera estatal da Venezuela (PDVSA), a restrição de atuação de empresas estrangeiras e a aproximação com Cuba, Iraque e a Líbia (vistos como inimigos dos EUA) avançam.

Se na política as relações não são boas, no comércio não se pode dizer o mesmo. Atualmente cerca de 500 empresas estadunidenses estão representadas na Venezuela, e os EUA mantêm investimento direto concentrado 
em grande parte no setor de petróleo e produção industrial naquele país. De acordo com o Departamento do Estado norte-americano, o regime cambial complexo do país, a queda das receitas de exportação de petróleo e a queda nos preços globais de petróleo privaram as empresas norte-americanas de acesso a dólares para enviar os seus lucros para fora da Venezuela. Além dessa situação adversa aos interesses dos EUA, as dificuldades para importar insumos industriais e produtos acabados para a Venezuela, a insuficiente de acesso a dólares, os controles de preços e regulamentações trabalhistas rígidas implementados pelo Estado venezuelano têm obrigado muitas empresas norte-americanas e multinacionais a reduzirem ou encerrarem as suas operações na Venezuela (U.S. Department of State 20I5).

\section{A estratégia da soberania adotada no Equador}

Rafael Correa é eleito em 2007 com o apoio da esquerda equatoriana. Embora tenha enfrentado tentativas de golpe e sequestro, em 2010, resgatado por militares apoiadores ao seu governo, Correa se mantém com altos índices de apoio da sociedade. Esta popularidade é muitas vezes explicada por teses de dominação tradicional, no sentido de Weber; é frágil, porém, a análise centrada unicamente na pessoa do presidente. Embora Correa seja um político jovem e com forte apelo popular, as políticas de inclusão social e de acesso dos mais pobres aos serviços básicos de educação e saúde explicam mais consistentemente o apoio popular que se mantém. Desta forma, trata-se de importante liderança carismática, mas com forte legitimidade das urnas. Com efeito, Correa é reeleito presidente em 2013 para mais quatro anos de mandado. Sua força eleitoral também se nota no referendum popular da nova Constituição Nacional5 que torna lei o domínio nacional sobre os setores estratégicos.

Em relação à política externa equatoriana, as suas diretrizes estão reunidas nos Planos de ação de governo Correa, Plan Nacional de Desarrollo 20072010 (Ecuador 2007) e Plan Nacional de Política Exterior 2006-2020, PLANEX 2020 (Ecuador 2006). Estes planos delimitam o nacionalismo como um dos eixos principais na política externa do país e isto significa atentar para

5 Rafael Correa, após oito anos e sete meses à frente do governo, foi avaliado positivamente por $52 \%$ dos entrevistados (Perfiles de Opinión 20I5. Acesso em 20 setembro de 20I5). No mesmo período, a Consultora Mitofsky de México após pesquisas fez um ranking de aprovação de presidentes, e Correa ficou em quarto lugar, perdendo para Danilo Medina de República Dominicana (89\%, com 33 meses no cargo), Evo Morales (75\%, com II3 meses no cargo), o panamenho Juan Carlos Varela (63\%, I2 meses). (Jornal Andes - Agência Pública de Notícias do Equador e Sul-América, 9 de setembro de 20I5.) 
relações com os países fronteiriços; considerar os Estados Unidos como potencial opositor à consolidação da democracia no Equador; manter relações com a Europa, com especial atenção à Espanha pelos vínculos históricos e culturais reforçados e pela a presença de mais de meio milhão de equatorianos no seu território; e considerar as relações com os países asiáticos, em especial China e Japão (Holguín 20I2, 43).

Em linhas gerais, Quito se acercará das posições de Venezuela e Bolívia e se distanciará da Colômbia em função das contendas de fronteira e da entrada das tropas colombianas no território equatoriano em perseguição às FARCS, em 2008. A aproximação do Irã e da Rússia, os tratados bilaterais de cooperação energéticas com a Venezuela - construção de refinaria e intercâmbio entre Pdvsa y Petroecuador - e a estratégia da integração regional pela criação da Unasul e ALBA são pautas na agenda externa equatoriana. Um dos maiores projetos de integração da infraestrutura na América do Sul está no Equador: o corredor fluvial e rodoviário que ligará a cidade brasileira de Manaus ao porto de Manta, no oeste equatoriano. Será um corredor para escoar mercadorias do continente via Pacífico, incrementar o comércio regional e oferecer uma rota alternativa ao canal do Panamá. A integração é estratégica para os países andinos e o para Brasil, haja vista ser o porto de Manta o porto latino-americano mais próximo da Ásia.

O porto de Manta é, assim, um ponto importante na condução da política externa equatoriana pela potencial integração. Mas também foi um tema conflituoso com os Estados Unidos. Por dez anos, de I999 a 2009, Manta foi base militar dos Estados Unidos para controle de narcotráfico, sendo considerado um enclave norte-americano no Equador. A não renovação do convênio que permitia aos Estados Unidos manterem essa base militar foi um dos eventos mais importantes nas relações bilaterais entre os dois Estados. Para o governo equatoriano, a presença dessa base militar significava uma perda de soberania e isto deveria ser reparado.

As relações com os Estados Unidos ficam estremecidas à medida que Quito questiona a forma de exploração das suas riquezas naturais, a dívida externa e as formas de inversões estrangeiras no país. Mas a tensão entre ambos países ganha proporções de rompimento diplomático quando, em abril de 20II, o governo de Correa declara o Embaixador norte-americano, Heather Hodges, persona non grata, e pede que este deixe o país ${ }^{6}$. Por fim, a aposta de Correa de acercar-se do Irã e da Rússia tem sido entendida como um dos elementos mais originais da sua política exterior, indicando um forte interesse

6 De acordo com a versão oficial, o pedido se deu em função das informações divulgadas pela rede Wikileaks sobre o conhecimento dos Estados Unidos acerca de tentativa de desestabilização do governo Correa. 
em se distanciar dos Estados Unidos.

A aproximação da Rússia com o Equador é visível, e o interesse daquele está ligado às questões energéticas. Em visita ao Equador, em 2008, o chanceler russo, Sergei Lavrov, expressou o interesse de seu país no mercado e na cooperação bilateral em diversas áreas, entre elas a formação acadêmica de estudantes latino-americanos, o comércio do petróleo, gás e no desenvolvimento da energia nuclear (Agência Brasileira de Inteligência 20I6). Mas a relação bilateral estratégica em termos comerciais é com a China. Atualmente se constroem em Equador, com importante aporte de capital chinês, vários projetos em setores estratégicos. Somente em 2015, foram assinados I5 convênios bilaterais, nove convênios no âmbito da cooperação, ciência, tecnologia e educação. Além disso, destaca-se o Acordo Mútuo de vistos para entrada nos respectivos países. Cidadãos chineses podem ingressar no Equador sem visto por 90 dias, enquanto que os equatorianos entram na China, sem o uso de visto, por um período de 30 dias. Esta é uma medida que sinaliza o interesse de Correa de se beneficiar do grande número de chineses que anualmente viajam pelo mundo, contribuindo para a entrada de divisas. Mas são as inversões chinesas no Equador que se destacam na relação bilateral, induzindo analistas a afirmarem que o endividamento externo do Equador teria apenas mudado de país, deixando de ser com os Estados Unidos para se deslocar para a China.

\section{A política externa boliviana: sócios, não patrões}

Quando Evo Morales assumiu o governo da Bolívia pela primeira vez, em 2006, o país encontrava-se entre as nações mais pobres do continente e na liderança dos países com maior número de golpes de Estado7. A vitória de Evo Morales e do intelectual Álvaro García Linera (vice-presidente), em 2005, com 53,74\% dos votos, abriu um espaço de possibilidades para mudanças semelhantes às verificadas nos governos Correa e Chavez. A diferença está, porém, no aprofundamento do reconhecimento das minorias étnicas, na discussão dos tipos de propriedade da terra e na criação dos tribunais de justiça indígenas. Em dez anos de governo, o país salta para os primeiros índices de crescimento econômico da região e rompe com a tradição de governos que não terminam os mandatos. Também na Bolívia é promovida uma nova Constituição ratificada em consulta popular, em $2009^{8}$, instituindo o "Estado

7 Evo Morales foi eleito em 2009 com 64\% dos votos e em 2014 com 61\% dos votos.

8 O mesmo processo de construção e ratificação de uma Constituição plurinacional foi realizado no governo de Correa, em 2008. 
plurinacional" e "intercultural" baseado na multiculturalidade (Ranincheski e Silva 20I2).

A relação entre a eleição de Morales e estas mudanças constitucionais com a política externa é direta. Pela terceira vez na história do país (I937, I969, 2006), a Bolívia decretou a nacionalização dos seus recursos naturais, sobretudo os setores do gás e da mineração. A Bolívia é um dos maiores produtores de prata, ouro, zinco e estanho. Conta com uma das maiores reservas de ferro do mundo, na região de El Mutún, sendo o Salar de Uyuni um dos maiores reservatórios de lítio do mundo. (CEDIB 2004).

Evo Morales adota a estratégia da defesa nacional, volta-se para a integração latino-americana e se destaca a necessidade de se implementar relações "justas" e simétricas com os interesses internacionais. O discurso produzido por Morales para marcar essa ideia é o lema "sócios, não patrões", abrindo espaço para críticas da oposição à esquerda e à direita, por razões distintas. A esquerda exige um projeto industrial e desenvolvimentista; a direita pressiona para a saída do presidente e o retorno do controle privado das riquezas minerais.

A diplomacia boliviana segue a ideia de soberania defensiva e prospectiva. A defesa e revalorização da plantação da folha da coca e o combate ao tráfico das drogas está inserida nesta estratégia. Para o governo de La Paz, a legalização da produção é uma questão de defesa nacional. Já o tráfico deve ser combatido de maneira compartilhada com a comunidade internacional sem abrir espaços para ingerências externas, principalmente a norte-americana, como ocorre na Colômbia. A política externa boliviana também atua em espaços tradicionais como a ONU, com discursos do presidente em favor do tema. Em setembro de 2008, La Paz expulsa a agência antinarcóticos dos Estados Unidos (DEA, sigla em inglês) e em 20I3 fez o mesmo com a agência de cooperação Usaid, ambas sob acusações de conspiração.

Usualmente a explicação para a defesa da coca pelo governo Morales se baseia na sua ligação histórica com o movimento sindical desde a década de I980. Ele foi da Confederação Sindical Única de Trabalhadores campesinos da Bolívia (CSUTCB) e da direção da Federação Especial do Trópico, uma das seis federações sindicais de produtores da folha da coca. No entanto, estas ações devem ser entendidas como políticas de governo que afetam as relações com os Estados Unidos, porque o problema do narcotráfico na região é importante na política norte-americana e para os países andinos (Avila 2007).

A diplomacia simultânea de defesa e reação aparece na forma com que a Bolívia passa a se relacionar com os Estados Unidos. O país tem levado a público um discurso de denúncia da ingerência dos Estados Unidos nos assuntos internos do país usando as organizações internacionais como expe- 
diente para pressionar e desestabilizar os governos ou grupos de esquerda na América Latina. As tensões se agravaram a partir de 2008 (com a expulsão do embaixador norte-americano do país), e, com a derrota de Evo Morales na consulta popular sobre uma lei que garantiria a sua reeleição indefinida, em fevereiro de 2016 , os conflitos tendem a ser mais intensos.

\section{As crises do bloco andino: construção de uma cultura da instabilidade}

As crises econômicas e políticas na Venezuela, Equador e Bolívia são frequentes e de longa data (sobre esse assunto, ver Oliveira 20I3). Mas o que torna as crises do último ano, 2015, fatores de análise mais detalhada é a maior pressão e algumas vitórias da oposição. Estas vitórias colocam em jogo a continuidade dos governos analisados e a atual configuração de política externa desses países andinos. Está em jogo a possibilidade de retorno de grupos políticos conservadores e alinhados com interesses internacionais alijados do poder nas duas últimas décadas.

As crises políticas foram uma constante no governo Chávez, sendo alvo, inclusive, de uma tentativa de golpe de Estado para destituí-lo, em abril de 2002. Por 48 horas, uma aliança entre a mídia, empresários, setores da Igreja Católica e militares o depôs da presidência. O respaldo dos EUA ao golpe de Estado se evidenciou na imediata visita que o seu embaixador em Caracas, Charles Shapiro, fez ao líder golpista Pedro Carmona, reconhecendo seu governo. Ao mesmo tempo, o FMI, anunciava, no mesmo dia, recursos financeiros para a Venezuela. Sem respaldo da população, das Forças Armadas e da comunidade internacional, a ação fracassou, e Chavez foi restituído ao governo venezuelano.

A radicalização das relações com os Estados Unidos avança a partir dessa tentativa de golpe. Os governos deixaram de ter embaixadores em 20Io e se relacionam com encarregados de negócios em suas representações diplomáticas, gerando um estancamento dos laços diplomáticos. Em 20II e 2013, a Venezuela sofre sanções dos EUA em função de sua relação comercial de energia com o Irã. A PDVSA é proibida de competir por contratos do governo nos EUA e de obter financiamento do Export-Import Bank dos Estados Unidos. Mas é a morte de Chavez, em março de 2013, que exigirá novas estratégias para prosseguir com o chamado projeto bolivariano. Nova eleição presidencial é realizada no mês seguinte e vence o candidato Nicolas Maduro, considerado o herdeiro de Chavez, sem o mesmo carisma e liderança no partido do antecessor. 
Assim a crise de abastecimento recorrente no governo Chavez ganha grandes proporções no governo Maduro. A falta de alimentos da cesta básica, levando a formação de longas filas, torna-se um fator importante para o descontentamento da população, lembrando em certa medida o período do governo Allende, no Chile, cujo desfecho foi o golpe militar perpetrado pelo General Pinochet em I973. O governo de Allende denunciou internacionalmente, inclusive em discurso na ONU a existência de uma guerra econômica não declarada entre o governo Nixon e o seu. Analistas destacaram, um ano após o golpe, que

a lição, se é que há alguma, nas relações entre os Estados Unidos e o governo Allende, é que um governo que está determinado a nacionalizar empresas norte-americanas sem compensações e a desenvolver um programa interno que efetivamente destrua sua capacidade de obter entrada de divisas não pode esperar receber subsídio para fazer isso nem do governo dos Estados Unidos nem de seus bancos ou empresas privadas (Sigmund I974, 38).

No caso venezuelano, o governo argumenta que os setores oligopolizados estão diminuindo deliberadamente a produção como forma de pressão; os setores produtivos, por sua vez, justificam que o ajuste de preços gerou perdas e com isso, para a indústria, a produção nacional fica sem estímulo. Muitos pararam de ordenhar as vacas porque isso deixou de ser negócio (Jar$\operatorname{dim}$ 2007).

As pressões internas sofridas pelos presidente Maduro, Correa e Morales questionam o projeto político que vem sendo implementado em cada país. As crises políticas que afetam o governo brasileiro e a derrota do grupo de Cristina Kirchner nas eleições de 20I5 afetam diretamente os três governos andinos. O novo presidente argentino, o conservador Mauricio Macri, representa a primeira possível quebra dos laços de cooperação que estes países vinham desenvolvendo na América do Sul. As declarações de Macri sobre a importância de se usar a cláusula democrática no Mercosul para questionar a permanência da Venezuela indicam novas configurações para as relações externas na América do Sul. Além disso, talvez o mais destacado seja a imediata eliminação dos impostos sobre as exportações de empresas mineradoras na Argentina.

O crescimento econômico de $5,5 \%$ ao ano em média durante os dois primeiros mandatos de Morales, o elogio recebido até mesmo do FMI e do Banco Mundial pelo desempenho das economias e o reconhecimento da erradicação do analfabetismo pela UNESCO, em 20I4, ${ }^{9}$ dificultavam a atuação

9 Irina Bokova, diretora da Unesco, destacou conquistas como o processo de erradicação do 
dos defensores do mercado liberal, dos grandes interesses econômicos nacionais e internacionais. A turbulência mundial do setor de minerais, de gás e petróleo revela uma situação interna preocupante dada a dependência dos três países na exportação das riquezas naturais. As previsões de crescimento do PIB para 20I6, do FMI, assinalam quedas na Venezuela, no Equador e na Bolívia.

Estas crises econômicas potencializaram a crise política institucional na Venezuela, por exemplo. Nas eleições parlamentares de 20I5, a oposição unificada, Mesa de la Unidade Democrática (MUD), fez I07 parlamentares (64,07\%), e o Partido Socialista Unido de Venezuela (Psuv) da situação fez 55 cadeiras, $(32,93 \%)$ conforme dados oficiais (Consejo Nacional Electoral (CNE) 20I5). A oposição certamente tentará via parlamento não só destituir o governo Maduro, mas promover mudanças mais radicais à direita. De acordo com um representante da oposição, o problema da Venezuela só pode ser solucionado com mudanças não conjunturais, mas estruturais (Guevara 20I6).

Assim como a Venezuela e Bolívia, as crises econômicas no Equador estão intrinsicamente ligadas às exportações do petróleo. Em dois momentos, 2009 e 20I5, o país enfrentou severas dificuldades em função da queda dos preços do barril. Se em 2009, a baixa se deu em função de diminuição de consumo, em 2015 a situação parece ser mais complexa em vista dos graves conflitos do Oriente Médio e da necessidade de acordos por preços entre os membros da OPEP, agência que regula a produção e o preço do Petróleo. Na primeira crise, a superação se deu pelas reservas que o país possuía em função da Lei para a Recuperação dos Recursos Petroleiros e pelo questionamento e não pagamento da dívida externa. Na crise de 2015, o governo possuía reservas para apoiar investimentos, mas continua com a dependência do país nas exportações do petróleo, mormente tenha outros produtos exportáveis como a banana, cacau e camarão.

As manifestações de rua que o Presidente Correa enfrenta em 2015 se somam às realizadas em 2009, 2010 e 2013, embora com pauta diferente: são contra o modelo político e econômico, mas também são contra projetos de lei enviados à Assembleia Nacional como imposto a heranças e renda. A lei de heranças vigente desde 2009 determina que os impostos sejam cobrados a partir do valor de 68.800 dólares. O projeto de lei previa mudar para 35.400 dólares, imposto a ser cobrado de forma progressiva. Os protestos foram tão expressivos que obrigaram o governo Correa a retirar o projeto da Assembleia. As manifestações de rua também eram contra o projeto de lei que aumentaria as taxas de exportação do petróleo, o que, segundo críticos, ocasion-

analfabetismo na Bolívia. Ver Naciones Unidas en Bolívia 2014. 
aria demissões no setor (El Tiempo 2015). Setores do movimento sindical de oposição a Correa apoiaram os protestos de rua, defendendo que se trataria de golpe duro contra os mais pobres já que eles pagariam pelo eventual aumento dos preços.

$\mathrm{Na}$ Bolívia as crises de instabilidade se mostram recorrentes. Apesar do avanço positivo que a Bolívia teve ao sair da marca histórica e tradicional de país mais pobre e instável do continente, as pressões internas se valem das quedas de preços de produtos primários no mercado internacional e avançam sobre o governo Morales. Entre os anos de 2006 e 20I5, a Bolívia teve uma queda significativa no desemprego (de Io,I\% para $4 \%$ no período), reduções expressiva da pobreza extrema, passando o salario mínimo de 500 para I. 656 pesos bolivianos, e da desnutrição, com queda da mortalidade infantil de 54,2 para 38 por mil. Esses indicadores, além da erradicação do analfabetismo reconhecido pela Unesco em 2009, tornaram Morales um governante bastante popular no meio internacional. No entanto, estes dados positivos não foram o suficiente para Morales vencer a consulta popular sobre a viabilidade de se candidatar ao quarto mandato.

O que se nota nos três países é a construção de uma cultura de instabilidade. Malgrado incontestáveis avanços nas questões sociais, entendidas como aquelas que afetam diretamente a qualidade de vida da população, especialmente dos menos favorecidos social e economicamente, disputas intestinas, como o apoio dos Estados Unidos e de órgãos internacionais, visam a derrubar os governos, mesmo que isso implique profundas rupturas sociais e econômicas. Em nome de divergências de caráter político-ideológico, é ameaçada a estabilidade econômica e política da região.

\section{Os Estados Unidos e as relações com os países andinos}

O poderoso think thank norteamericano Council on Foreign Relations apresentou em 2008 o informe do chamado Grupo de Trabalho Independente com resultados de estudos e discussões sobre as relações entre Estados Unidos e América Latina. O Informe ${ }^{\mathrm{Io}}$ sinaliza o fim da era dos Estados Unidos como país dominante na América Latina e sugere que seja reestruturada a política para o continente latino-americano em quatro áreas consideradas

Io O Council on Foreign Relations (CFR) se define como uma organização independente e formada por um grupo de especialistas e editora dedicados a servir como fonte de ideias para funcionários de governo, executivos corporativos, jornalistas, estudantes, líderes cívicos y religiosos e outros interessados em entender as opções de política exterior dos Estados Unidos e outros países. Fundado em I92I, o CFR publica a Foreign Affairs, a revista mais importante em assuntos internacionais e em política exterior dos Estados Unidos (CFR 2008). 
como críticas: a pobreza e desigualdade, porque alimenta insatisfações; a segurança pública; a migração e a segurança energética. Estes pontos seriam de preocupação imediata dos governos e população latino-americana e, neste caso, de fácil retomada de influência dos Estados Unidos (CFR 2008).

Esta estratégia contornaria a crescente desconfiança da população venezuelana, boliviana e equatoriana em relação aos Estados Unidos pois

esta desconfiança geral aos Estados Unidos permitiu que os presidentes Hugo Chávez da Venezuela, Evo Morales da Bolívia, Rafael Correa do Equador e inclusive Felipe Calderón do México busquem reforçar o apoio popular nacional com suas críticas a Washington (CFR 2008, 7).

Para os autores desse Informe, as políticas antiamericanas do presidente Chavez deveriam ser levadas a sério pelos Estados Unidos. A omissão dos Estados Unidos e o isolamento de certas nações reduziriam a sua influência, ao mesmo tempo que, de maneira involuntária, fortaleceriam os regimes desses países, como teria demonstrado a experiência com Cuba (CFR 2008, 75).

Se os norte-americanos também queriam evitar que Hugo Chávez se transformasse em vítima, em um segundo Fidel Castro, segundo Bandeira (2003), a administração Clinton preferiu evitar custos políticos e econômicos, no âmbito nacional e regional, e tomou a atitude de wait and see. Os anos seguintes mostraram que se processaria o que o Informe queria evitar: Equador e Bolívia elegeram governos progressistas, o Mercosul foi recuperado como parte importante da integração regional e criaram-se novos dois blocos importantes, a Unasul e a IRSA.

Mesmo com fim da bipolaridade nos anos I990 e a influência da China e da Rússia no cenário internacional, os Estados Unidos continuam desempenhando um papel determinante nas relações internacionais. Para Pecequilo (20I2), nem os Estados Unidos declinaram o suficiente para darem lugar a uma nova hegemonia, nem as novas potências ascenderam para tomar o seu lugar. O tipo de ordem construída gerou a peculiar interdependência político-econômica, situações de vulnerabilidade mútua e do paradoxal compartilhamento de interesses dos Estados Unidos com seus desafiadores.

A entrada dos chineses e seus investimentos igualmente se processou com rapidez. A presença da China na América Latina vem ganhando destaque nos últimos anos, com investimentos em média cerca de US \$ Io bilhões por ano em países da América Latina, com uma presença significativa em muitos setores e indústrias, particularmente em petróleo, mineração e na infraestrutura. Dados da CEPAL indicam que 
a China já é a segunda maior fonte de importações da região, e o terceiro principal destino de suas exportações. Entre 2000 e 20I4, sua participação nas exportações regionais aumentou de I\% para 9\% (em 20I3 alcançou I०\%), enquanto a sua participação nas importações aumentou de pouco mais de $2 \%$ para I6\%. Assim, em 20I4 a China e a União Europeia (UE) tiveram praticamente a mesma participação no comércio de bens da América Latina e o Caribe com o mundo (I2,4\% e I2,5\%, respectivamente). Embora a UE continue a ser o segundo maior mercado para as exportações regionais, atrás dos Estados Unidos, desde 2010 a China a deslocou como a segunda principal fonte de suas importações, também atrás daquele país (CEPAL 20I5, 37).

Essa aproximação da China na América Latina foi silenciosa, rápida e cautelosa uma vez que se trata de área de influência norte-americana (Visentini 20I4). Provavelmente os Estados Unidos monitoram essa aproximação com preocupação.

As estratégias dos Estados Unidos nas últimas duas décadas se agrupam em três grandes eixos que seriam o Engajamento \& Expansão (I994), a Doutrina Preventiva (2002) e a Doutrina Obama (2010) (Pecequilo 20I2). Para a América Latina, a postura dos Estados Unidos se deu na Iniciativa para as Américas (IA) do presidente Bush, lançada em I990, propondo a criação de uma zona hemisférica de livre comércio; no Tratado de Livre Comércio da América do Norte (NAFTA) entre os Estados Unidos, Canadá e México, entrando em vigor em I994; e a Área de Livre Comércio das Américas (ALCA). Estas iniciativas, porém, completado mais de duas décadas, não se expandiram (Visentini 20II).

$\mathrm{O}$ uso da força, o apoio a golpes de Estado e quedas de governos são parte das estratégias norte-americanas que permanecem, embora em menor grau e intensidade. As denúncias a estes expedientes são feitas pelas próprias agências norte-americanas. A National Endowment for Democracy (NED) denunciou publicamente o que a CIA tinha tranquilamente feito há décadas (Gaudichaud 20I5). Outras vezes, são documentos oficiais que se tornam públicos, via a plataforma WikiLeaks, como os que mostram o financiamento da oposição venezuelana pelos Estados Unidos desde a chegada ao governo de Hugo Chavez em I998 (Johnston 20I4). Especialistas na área analisam o envolvimento dos Estados Unidos na região e concluem que as principais lideranças norte-americanas tomam conhecimento prévio dos eventos. Este foi o caso do Director of Central Intelligence, George Tenet, e o Secretário de Estado de George W. Bush, Colin Powell, que sabiam dos preparativos para depor o presidente Chavez em 2002 (Bandeira 20I4). 
Do ponto de vista da agenda da segurança, os Estados Unidos consideram que a América Latina não enfrenta grandes riscos imediatos em termos de expansão do terrorismo e ameaças de conflitos armados (Ayerbe 2008). Esta percepção norte-americana não significa, porém, a retirada suas bases militares da região. A manutenção da presença militar norte-americana tem sido, há pelo menos duas décadas, justificada pelo combate ao narcotráfico, e com esse argumento implementaram, por exemplo, um dos maiores programas de ajuda financeira a um só país, o controvertido Plan Colômbia. Os Estados Unidos mantêm em atividade suas operações militares no continente latino-americano, e atualmente é dirigido pelo Comando Sul do Departamento de Defesa norte-americano para operacionalizar as decisões político-estratégicas para a América Latina e o Caribe ${ }^{\text {II }}$. O Comando Sul atua em duas grandes áreas: Cone Sul com os objetivos de "preparação das Forças Armadas para operações de paz, democratização, profissionalização das Forças Armadas e fortalecimento da segurança nacional"; e o Arco Andino, com o propósito de "combate ao narcotráfico, democratização, profissionalização das Forças Armadas e combate a ameaças transnacionais" (Abreu 2002, I4).

Sob o Comando Sul, atualmente existem duas "Localidades de Operações Avançadas (Forward Operating Locations - FOL)": Rainha Beatrix/Hato (Aruba/Curaçao) e Comalapa (El Salvador). Havia uma terceira, localizada em Manta (Equador), mas foi desativada com a recusa do presidente Rafael Correa em renovar a concessão, gerando mais um ponto de atrito com os Estados Unidos como sinalizamos anteriormente. A alternativa para os Estados Unidos foi negociar com a Colômbia e o Chile. As três FOL, se Manta permanecesse sob controle dos Estados Unidos, significariam a presença e o monitoramento do espaço aéreo na América Latina e no Caribe, incluindo parte do território brasileiro, particularmente a região amazônica (Abreu 2002).

Do ponto de vista das campanhas ideológicas realizadas pelos Estados Unidos, a exportação da democracia e do seus valores liberais tem sido uma das grandes políticas externas dos Estados Unidos para o mundo e, por consequência, para a América Latina (Castro 2014). Com base nesse discurso, os Estados Unidos se veem no direito de interferir e opinar sobre a política interna dos países. Ilustração disso é a recente eleição para o Congresso venezuelano discutida acima. Imediatamente à proclamação da vitória da oposição a Maduro, o próprio Secretário de Estado, John Kerry, expressa a satisfação do

II É um Comando Combinado composto por elementos do Exército, Marinha, Força Aérea e Fuzileiros Navais, além de contar com representantes do Departamento de Estado, da Drug Enforcement Administration (DEA), da Defense Intelligence Agency (DIA), da National Security Agency (NSA), da Guarda Costeira e da Alfândega, com um total aproximado de 850 homens e mulheres das três Forças Armadas e I30 civis. 
seu país com o resultado. Nas suas palavras,

eleitores venezuelanos expressaram seu desejo irresistível para uma mudança no comando do seu país. O diálogo entre todas os partidos na Venezuela é necessário para enfrentar os desafios sociais e econômicos que o país enfrenta, e os Estados Unidos estão prontos para apoiar tal diálogo, juntamente com outros membros da comunidade internacional (Kerry 2015).

Como afirma Villa (2003), após a guerra fria, os Estados Unidos passam a punir países que aceitam princípios de governabilidade internacionais análogos aos dos países socialistas, mas com grandes dificuldades para efetivá-los. Persiste assim o padrão de atuação dos Estados Unidos, isto é, o discurso da ingerência em outras regiões e países com o pretexto de "defender os povos oprimidos", "promover a democracia", "destituir ditaduras" e "garantir as liberdades individuais" (Santos e Teixeira 2015, Castro 2014).

\section{Conclusão}

A particularidade dos governos Chavez/Maduro, Rafael Correa e Evo Morales se reveste de significado histórico para a política internacional, haja vista as relações externas voltadas para a integração regional, a retomada do controle da exploração das riquezas minerais e energéticas (algumas das maiores do mundo), a aproximação com a China e a Rússia. Os Estados Unidos, anteriormente hegemônico, perdem espaços políticos e são questionados quanto às tentativas de ingerência nos assuntos internos destes países.

Estas novas estratégias implementadas pelos três países andinos são decorrências das decisões domésticas, igualmente históricas para cada uma daquelas sociedades, particularmente para o Equador e a Bolívia, que se transformaram de países extremamente pobres, com populações analfabetas e sem assistência social do Estado, em países com efetivos processos de erradicação do analfabetismo, diminuição das desigualdades sociais e reconhecimento constitucional das minorias étnicas. Ao contrário do discurso de repressão à oposição nestes países, ela sempre existiu de forma ativa, participando e sendo derrotada em pleitos eleitorais e, ao mesmo tempo, organizando e patrocinando protestos e tentativas de golpes de Estado.

Passados i 6 anos, os três governos se mantêm no poder via sucessivas eleições. Nos dois últimos anos, porém, dão sinais de fragilidades na política interna, abrindo espaços para as indagações sobre o futuro da política externa, caso venham a sair do governo. A primeira conclusão é a possível 
reversão da política externa soberana que estes governos vêm adotando, sobretudo em relação aos Estados Unidos. As oposições representam interesses próximos dos norte-americanos, prejudicados pela redefinição das políticas econômicas. Mecanismos constitucionais, criados e referendados pela sociedade, como o Direito Plurinacional, no entanto, podem ser obstáculo às tentativas de retorno àquelas condições políticas anteriores.

Outra conclusão deste artigo é a importância da questão ideológica como categoria de ação, de projeto e de discernimento entre os diversos projetos de governo e de política externa adotados. A relação com os Estados Unidos, a nacionalização dos recursos do solo e a opção pela integração e cooperação Sul-Sul sem o pragmatismo usual podem ser explicados pela dimensão ideológica. Esta questão, no entanto, merece aprofundamento em relação ao contínuo esquerda-direita para o entendimento dos projetos adotados. A cultura política e a questão ideológica de cada país importam para a compreensão da política internacional e das relações externas de uma região. Não se tratam de meras relações entres os Estados-Nacionais, mas de interesses que se articulam em escalas nacional e internacional. A política nacional das duas últimas décadas na Venezuela, Equador e Bolívia se constituem em exemplo do quanto decisões domésticas afetam o cenário internacional e definem a política externa a ser adotada. São realidades ricas em exemplos do quanto o embate ideológico ainda é um fator decisivo na compreensão dos movimentos da política internacional. A multipolaridade atual nas relações internacionais em muita medida é fruto das decisões internas dos países.

Não menos importante é a constatação da estreita interdependência da estabilidade política dos países andinos. Cada vez mais fica claro que decisões ou eventos que modifiquem a direção da política interna (e externa) de um dado país da região implicará reações em outros. Um exemplo emblemático foram as jornadas de protestos de 2015 no Equador. Diferentemente das anteriores, igualmente fortes e organizadas, as últimas tiveram consequências na desestabilização do governo Correa. A explicação para a mudança não está apenas em um esperado desgaste interno de um governo que se reelege, mas na conjuntura desfavorável que os vizinhos governos Maduro, na Venezuela, e Morales, na Bolívia, enfrentavam à época.

Por fim, a análise realizada reforça a necessidade de entendermos e compreendermos o funcionamento da cultura política dos países e a sua relação com a questão externa. Tanto os Estados Unidos quanto as sociedades andinas possuem valores e crenças que se expressam em apoio a diretrizes e motivações para as ações políticas. Tratar conjuntamente estas dimensões não é simples, mas podem ser úteis para a compreensão da relevância que temas como democracia, participação, liberdade, nacionalismo, autonomia, sol- 
idariedade, independência podem ter para estas sociedades. Estas dimensões ajudam a entender o nível do envolvimento e compreensão da sociedade nas definições das políticas externas dos seus países. A opinião pública é parte importante no desfecho das decisões nacionais e de política externa, dada a sua interdependência. Com efeito, os governos com posturas de esquerda aqui analisados e os atritos e conflitos com interesses norte-americanos podem implicar distanciamento da comunidade nacional com os Estados Unidos. Foi com essa compreensão que analisamos as recentes crises na Venezuela, Equador e Bolívia e os seus efeitos na política externa e na política internacional de cada um e da região.

\section{REFERÊNCIAS}

Abreu, José Alberto da Costa. 2002. A presença militar dos EUA na América do Sul. Rio de Janeiro: Escola do Comando e Estado-Maior do Exército.

Agência Brasileira de Inteligência (ABIN). 20I6. Moscou também quer ajudar Equador a ter tecnologia. Fevereiro 2016.

Avila, Jean Paul. 2007. "Bolívia: processos de mudança e política externa." Revista Diplomacia, Estratégia e Política/Projeto Raúl Prebisch No. 8: 36-48.

Ayerbe, Luis F. 2002. Estados Unidos e América Latina. São Paulo: Unesp.

Ayerbe, Luis F. 2008. "Governos de esquerda na América Latina e a perspectiva da política externa dos EUA." Perspectivas 33: 213-232.

Bandeira, Luiz Alberto Moniz. 2003. "Os Estados Unidos e a crise na Venezuela.” Revista Espaço Acadêmico n. 20 (jan).

Bandeira, Luiz Alberto Moniz. 20Io. Brasil, Argentina e Estados Unidos - Conflito. São Paulo: Civilização Brasileira.

Bandeira, Luiz Alberto Moniz. 2014. Brasil, Argentina e Estados Unidos: conflito e integração na América do Sul (da Tríplice Aliança ao Mercosul), 18702007. Rio de Janeiro: Civilização Brasileira.

Bernal-Meza, Raúl. 2005. "Multilateralismo e unilateralismo na política mundial: América Latina frente à ordem mundial em transição." Revista Brasileira de Política Internacional 48 (I): 5-23.

Carmo, Corival Alves do. 2008. "As três vertentes da política externa de Hugo Chávez.” Jornal da Unesp. Ano XXII, No. 235.

Castro, Henrique Carlos. 20I4. Cultura Política Comparada: democracia e mudanças econômicas - Brasil, Argentina e Chile. Brasília: Verbena.

CEDIB. 2004. Base de datos sobre recursos naturales: Bolivia - Estadísticas del 
sector minero.

CEPAL. 20I5. América Latina y el Caribe y China hacia una nueva era de cooperación económica. Santiago: Naciones Unidas.

Coatsworth, John H. 20I0. "The Cold War in Central America, I975-I99I." In The Cambridge history of the cold war Vol. III, editado por Melyyn P. Leffler e Odd Arne Westad. Cambridge: The University Press.

Consejo Nacional Electoral (CNE). 2015. Resultados electorales 2015: elecciones Asemblea Nacional. Caracas.

CFR, Council on Foreign Relations. 2008. Relaciones Estados Unidos-América Latina: una nueva dirección para una nueva realidad. New York.

Dinges, John. 2008. Les Années Condor: Comment Pinochet et ses alliés ont propagé le terrorisme sur trois continentes. Paris: La Découverte.

Ecuador. 2006. "Plan Nacional de Política Exterior 2006-2020. PLANEX 2020." Ministerio de Relaciones Exteriores, Quito. http://www.cancilleria.gob.ec/wp-content/uploads/2013/05/planex_2020.pdf

Ecuador. 2007. "Plan Nacional de Desarrollo 2007-2010: planificación para la revolución ciudadana." Gobierno Nacional de la República del Ecuador, Quito. http://www.planificacion.gob.ec/wp-content/uploads/downloads/2013/09/Plan-Nacional-Desarrollo-2007-2010.pdf

El Tiempo. 20I5. Bolivia. Bogotá, I3 de março. eltiempo.com.ec

Ellner, Steve. 2008. "Las tensiones entre la base y la dirigencia en las filas del chavismo." Revista Venezolana de Economía y Ciencias Sociales I4(I): 49-64.

Fuentes, Claudio. 2004. Bajo la mirada del Hakon: Estados Unidos - América Latina post 11/09/2001. Santiago: FLACSO-Chile.

Gaudichaud, Franck. 20I5. "De Santiago a Caracas, la main noire de Washington." Le Monde Diplomatique juin: I8-I9.

Guevara, Freddy. 20ı6. "Antes de que finalice febrero anunciaremos al país em mecanismo constitucional para cambiar em gobierno." Unidad Venezuela, I3 de fevereiro. http://unidadvenezuela.org/2016/02/freddy-guevara-antes-de-que-finalice-febrero-anunciaremos-al-pais/

Holguín, Galo Yépez. 20I2. "La actual política exterior del Ecuador y su relación con la nueva Constituición." Revista Afese.

Jardim, Claudia. 2007. "Venezuela enfrenta crise de abastecimento." BBC Brasil, I5 de novembro. Acesso em 20I6. http://www.bbc.com/portuguese/reporterbbc/story/2007/II/O7III5_venezuelacriseml.shtml

Johnston, Jake. 20I4. "What the Wikileaks cables say about Leopoldo López." 
Center for Economic and Policy Research 2I de fevereiro. Acesso em 20I6. http://cepr.net/blogs/the-americas-blog/what-the-wikileaks-cables-say-about-leopoldo-lopez .

Kagan, Robert. 20I2. The World America made. New York: Alfred Knopf.

Kerry, John. 20I5. "Press Statement on Venezuelan Legislative Elections." Press Releases: 2015, I2 de julho. Washington, DC. http://www.state. gov/r/pa/prs/ps/20I5/

Kissinger, Henry. 20I5. Ordem Mundial. Rio de Janeiro: Objetiva.

Naciones Unidas en Bolívia. 20I4. “Unesco subraya logro de erradicación del analfabetismo en Bolivia e inclusión educativa.”. I7 de junho. http:// www.nu.org.bo/noticias/destacados-nacionales/unesco-subraya-logro-de-erradicacion-del-analfabetismo-en-bolivia-inclusion-educativa./

Nye, Joseph S. I990. Bound to lead. New York: Basic Books.

Nye, Joseph S. 2002. The Paradox of American Power. New York: Oxford University.

Oliveira, Renata Peixoto de. 2013. "Pós-neoliberalismo e a configuração de novas alianças políticas na América Latina: Bolívia, Venezuela e Equador." Revista Comunicação Q Política 30 (2): 27-47.

Pecequilo, Cristina Soreanu. 2orr. A Política Externa dos Estados Unidos: continuidades e mudança. Porto Alegre: UFRGS,.

Pecequilo, Cristina Soreanu. 2012. As Relações Brasil-Estados Unidos. Belo Horizonte: Fino Traço.

Pecequilo, Cristina Soreanu. 20I2. Os Estados Unidos e o século XXI. Rio de Janeiro: Elsevier.

Pomar, Valter. 20ıо. “A política externa do Brasil." In Consenso Progresista. Política exterior de los gobiernos progresistas del Cono Sur: convergencias $y$ desafíos, organizado por Yesko Quironga e Cassio França, 63-96. São Paulo: Fundación Friedrich Ebert.

Ranincheski, Sonia, e G. J. Silva. 20I2. "Bolivia, siglos XX y XXI: pluriculturalismo, indigenismo y política.” Relaciones Internacionales (La Plata): II5-I38.

Santos, Maria Helena de Castro, e Ulysses Tavares Teixeira. 2015. "Interests and Values in Obama's Foreign Policy: leading from behind?" Revista Brasileira de Política Internacional 58 (2): II9-I45.

Santos, Maria Helena. 20ıо. "Exportação de Democracia na Política Externa Norte-Americana no Pós-Guerra Fria: doutrinas e o uso da força." Revista Brasileira de Política Internacional 53 (I): I58-I9I. 
Sigmund, Paul E. I974. "El bloqueo invisible y la caída de Allende." Revistas Estudios Internacionales 7 (26): 20-38.

Teixeira, Tatiana. 2007. Os think tanks e sua influência na politica externa dos EUA. Rio de Janeiro: Revan.

U.S. Department of State. 20I5. "U.S. Relations with Venezuela." Bureau of Western Hemisphere Affairs, 20 de julho. http://www.state.gov/r/pa/ ei/bgn/35766.htm

Villa, Rafael. 2003. "A questão democrática na agenda da OEA no pós-Guerra Fria." Revista Brasileira de Sociologia e Política 20: 55-68.

Visentini, Paulo Gilberto Fagundes. 20Iı. "Brasil, America del Sur y America Latina y el Caribe: Oportunidades y desafíos de la integración.” In America Latina y el Caribe. Multilateralismo vs Soberania: la construcción de la Comunidad de Estados Latinoamericanos y caribeños, editado por Francisco Rojas Aravena, III-I34. Buenos Aires: Teseo/FLACSO.

Visentini, Paulo Gilberto Fagundes. 20I4. "A Ásia no Sistema Internacional e a China como Pivô.” Revista Conjuntura Internacional II (I): 83-9I.

Vizentini, Paulo Gilberto Fagundes, e Marianne Wiesebron. 2006. Neohegemonia Americana ou Multipolaridade? Pólos de Poder e Sistema Internacional. Porto Alegre: UFRGS.

\section{RESUMO}

O artigo trata da política externa recente dos países andinos, Venezuela, Equador e Bolívia, considerando a relação com os Estados Unidos e a conjuntura de crises políticas nestes países. Discutimos o contexto nacional de cada país e os desdobramentos para as relações externas e para a política internacional de cada um e da região. Abordamos o interesse dos Estados Unidos nos efeitos das atuais crises nos três países e destacamos a importância da cultura política para a compreensão da realidade.

\section{PALAVRAS-CHAVE}

Política Externa; Países Andinos; Estados Unidos.

Recebido em 01 de março de 2016. Aprovado em 28 de junho de 2016. 